\title{
It's Time for Refractories!
}

Once a year we take one issue of the Interceram to focus on refractory materials. Why? Because these materials are the basis for the manufacturing of products made of steel, copper, aluminum, glass and plastics, which could not be produced without them. Refractories are the key to all those materials that form the goods that we need in our everyday lives.

This industry is shaped significantly by its associations and organizations that lead research initiatives, create a strong network between individual parties and strengthen national and international collaborations. In this issue we want to focus on some of the people who are in the foreground of these actions and let them give us a perspective on what moves the industry. One key topic is, without question, the matter of recycling of refractory materials. And there are many questions to be answered, like where do we stand on an international and a national level, what actions are being taken already, and what is the outlook for recycled refractories. This issue might provide some answers.

In this context it is also interesting to take a closer look at the material itself and to find out if alternatives could be more sustainable and $\mathrm{CO}_{2}$ neutral. For example, a new high-temperature insulation material was created from rice husk ash, a natural raw material that is eco-friendly.

Secondary raw materials for refractories are also part of the program of this year's International Colloquium on Refractories, which is already online with a brand new website and will be held as a digital event in September. See you at the virtual exhibition!

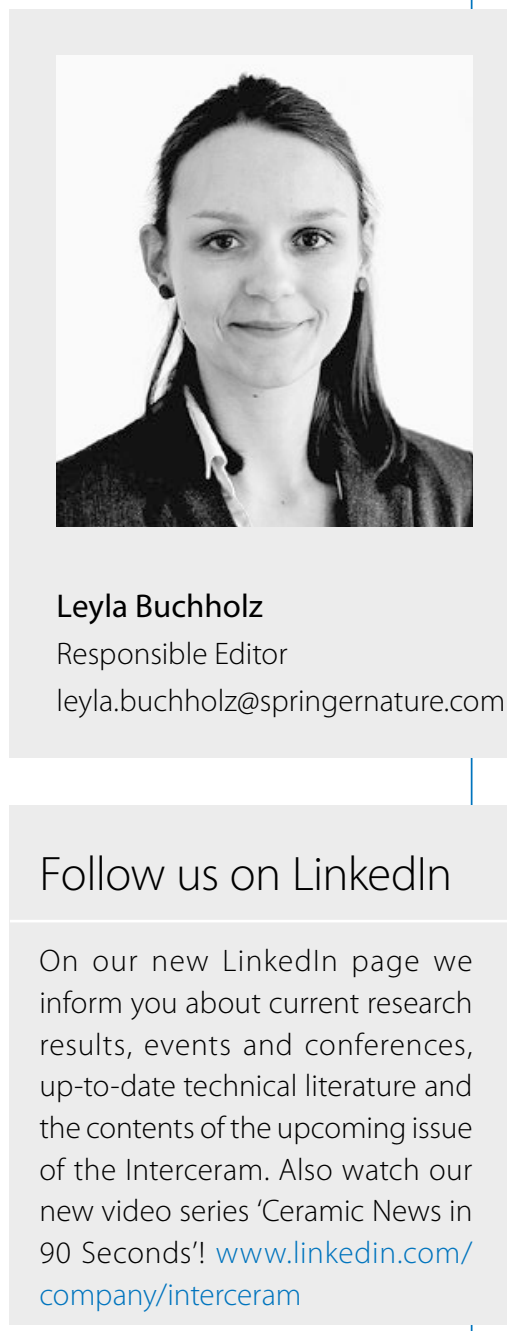

